\title{
1991 MRS-Korea Conference and Aeronautics-Space Materials Exhibition Held in Seoul
}

The first MRS-Korea Conference and Aeronautics-Space Materials Exhibition, sponsored by the Materials Research Society of Korea, was held at the Olympic Youth Hostel, Seoul, Korea, on November 15-16, 1991. The conference was designed as a forum to exchange information on research and development progress and research interests on materials science and engineering, with a special emphasis on aeronautics-space materials.

More than 100 papers were presented in the areas of electronic and magnetic materials, composites, sensors, alloys, surface characterization as well as aeronauticsspace materials. In addition, about 30 private companies participated in the materials exhibitions, which overwhelmingly attracted public attention. The exhibit was held simultaneously with symposia for the first time in Korea, and it complemented the technical program very well.

In addition to the regular paper presentations, the following invited talks were given:

"Materials Research under High Pressure," Toshimi Yamane, Department of Materials Science and Engineering, Osaka University, Japan.

"Korean Aeronautics-Space Industries and Technological Development," Jae Hak Hong, President of Korean AeronauticsSpace Research Institute.

"Present and Future of Korean Aeronautic Materials Industries," Hak Min Kim, Korea Institute of Machinery and Metals.

"The Bonding of Aircraft Materials," Yoshikuni Nakao, Production and Processing Engineering Department, Osaka University, Japan.

"MOCVD in Semiconductor and Superconductor Technology," Fedor A. Kuznetsov, Director of Institute of Inorganic Chemistry, Academy of Science of the U.S.S.R.

"Recent Trends of R\&D in Steel Long Products," Fukukazu Nakasato, Chief Manager, Kokura Steel Works, Sumitomo Metal Industries, LTD, Japan.

\section{Other News from MRS-Korea}

- Last August, the executive council of MRS-Korea approved Chon's recommendation to have the following distinguished scientists as honorary members of MRSKorea: R.P.H. Chang, president of IUMRS, Northwestern University, U.S.A.; and Shigeyuki Sömiya, president of MRS-Japan, Nishi Tokyo University, Japan.
- MRS-Korea is publishing the Korean Journal of Materials Research bi-monthly.

- The 1992 Spring MRS-Korea Conference will be held in Taejon in May 1992.

For more information about MRS-Korea, contact: MRS-Korea Office, Seongdong P.O. Box 4, Seoul 133-600, Korea; phone 822- 297-6771; fax 82-2-291-0578.

\section{1-1992 Officers of MRS-Korea}

President: Min Che Chon

Vice Presidents: Jin Tae Song, Soon Ja Park, Ki Suck Maeng, Kye Hwan Oh

General Secretaries: Yoon Woo Park, Jong Wan Park

Auditors: Su Hyon Paek, Kwang Hyun Ro Editors: Sang Yun Lee, Hyun Ku Chang, Kwang Soo No, Won Ho Jo

Planning Secretaries: Chong Ho Kim, Kil Sung Churn, Won Ho Kang, Chung Nam Whang

Technical Secretaries: Ho Gi Kim, Sokeel Yoon, Rae Woong Chang

Treasurers: Jae Duk Lim, Seon Jin Kim

Advisers: Kee Hyong Kim, Byong Sik Jeon

\section{E-MRS Holds Summer School on Laser Ablation of Electronic Materials}

Because laser ablation etching and deposition of solids for microelectronics has received much attention in recent years, it seemed important, for both scientific and technological reasons, to bring together leading scientists from universities, national laboratories, and industries to determine the status of ablation of solids including dielectrics, metals, semiconductors, superconductors, and polymers and to discuss future opportunities of this process for materials science and technology.

The E-MRS Summer School on Laser Ablation of Electronic Materials, cochaired by E. Fogarassy (CNRS-Strasbourg, France) and S. Lazare (University of Bordeaux, France) was held September 1619, 1991 at Carcans Maubuisson (Gironde) in France under the auspices of the European Materials Research Society, and was sponsored by the European Networks and IBM-France. More than 90 participants attended, including scientists and engineers from Japan, the United States, and 10 European countries including Russia, providing a large and detailed overview of fundamentals and applications of laser ablation processing.

The four-day program consisted mainly of 20 invited review lectures and 12 latenews communications. All participants were free to present their work during the poster sessions to exchange information and interact directly with expert scientists.

A special exhibition allowed industry representatives to display equipment, such as laser sources (Lambda-Physik, Sopra), laser ablation and processing systems (ISA- Riber, Exitech Ltd, Varian), and instrumentation (Perkin-Elmer).

The scientific program was divided into three main parts: basic mechanisms of ablation; diagnostics used in determining mechanisms; and applications in new materials synthesis, surface patterning, and instrumentation. J.F. Eloy (CEA-CESTA,
France) led off the program with a historical overview of laser ablation during the last 20 years.

\section{Basic Mechanisms}

General aspects of laser solid interactions, particularly with respect to laser ablation, were discussed in detail by $D$. Bauerle (Linz University, Austria). Invited contributions dealt with the basic mechanisms of laser ablation of various solids, such as metals (M. von Allmen (consultant, Switzerland) and polymers (R. Srinivasan (UVTech Associates, U.S.A.) and M. Stuke (Max-Planck-Institut, Germany) and comparisons of the processes in relation to the materials' target properties. In this area, R.W. Dreyfus (IBMWatson, U.S.A.) reviewed theoretical and experimental aspects of the ablation of metals and dielectrics. J. Brannon (IBMAlmaden, U.S.A.) focused on copper and polymer photoablation. 